\title{
Lymphatic filariasis control in Tanzania: effect of six rounds of mass drug administration with ivermectin and albendazole on infection and transmission
}

\author{
Paul E Simonsen ${ }^{1 *}$, Yahya A Derua ${ }^{2}$, William N Kisinza ${ }^{2}$, Stephen M Magesa ${ }^{3}$, Mwele N Malecela ${ }^{4}$ \\ and Erling M Pedersen ${ }^{1}$
}

\begin{abstract}
Background: Control of lymphatic filariasis (LF) in most countries of sub-Saharan Africa is based on annual mass drug administration (MDA) with a combination of ivermectin and albendazole, in order to interrupt transmission. We present findings from a detailed study on the effect of six rounds of MDA with this drug combination as implemented by the National Lymphatic Filariasis Elimination Programme (NLFEP) in a highly endemic rural area of north-eastern Tanzania.

Methods: The effect of treatment on transmission and human infection was monitored in a community- and a school-based study during an 8-year period (one pre-intervention and 7 post-intervention years) from 2003 to 2011.

Results: Before intervention, $24.5 \%$ of the community population had microfilariae $(\mathrm{mf})$ in the blood, $53.3 \% \mathrm{had}$ circulating filarial antigens (CFA) and 78.9\% had specific antibodies to the recombinant filarial antigen Bm14. One year after the sixth MDA, these values had decreased considerably to $2.7 \%, 19.6 \%$ and $27.5 \%$, respectively. During the same period, the CFA prevalence among new intakes of Standard 1 pupils in 10 primary schools decreased from 25.2\% to 5.6\%. In line with this, transmission by the three vectors (Anopheles gambiae, An. funestus and Culex quinquefasciatus) as determined by dissection declined sharply (overall vector infectivity rate by $99.3 \%$ and mean monthly transmission potential by $99.2 \%$ between pre-intervention and fifth post-intervention period). A major shift in vector species composition, from predominantly anopheline to almost exclusively culicine was observed over the years. This may be largely unrelated to the MDAs but may have important implications for the epidemiology of LF in the area.

Conclusions: Six MDAs caused considerable decrease in all the measured indices for transmission and human infection. In spite of this, indices were still relatively high in the late period of the study, and it may take a long time to reach the recommended cut-off levels for interruption of transmission unless extra efforts are made. These should include increased engagement of the target population in the control activities, to ensure higher treatment coverage. It is expected that the recent initiative to distribute insecticide impregnated bed nets to every household in the area will also contribute towards reaching the goal of successful LF elimination.
\end{abstract}

\footnotetext{
* Correspondence: pesi@sund.ku.dk

'DBL - Centre for Health Research and Development, Faculty of Health and Medical Sciences, University of Copenhagen, Thorvaldsensvej 57, 1871

Frederiksberg C, Denmark

Full list of author information is available at the end of the article
} 


\section{Background}

Lymphatic filariasis (LF), a disfiguring and disabling disease caused by a mosquito-borne parasitic infection, is a major public health problem in many developing countries with a warm and humid climate. The causative nematode parasite in sub-Saharan Africa is Wuchereria bancrofti, and it has been estimated that more than 45 million people are affected in this region [1]. The parasites are transmitted to humans when infected mosquito vectors deposit infective larvae onto the human skin [2]. The larvae penetrate the skin, migrate to the lymphatic vessels, and develop into male and female adult worms over a period of months. Mature and fertilized female worms release large numbers of minute microfilariae $(\mathrm{mf})$ which circulate in the blood. Mf ingested by a vector during a blood meal will develop to infective larvae in about 10-14 days. These migrate to the mosquito's proboscis and may then be transmitted to a new human host during a subsequent blood meal. The mosquito vectors thus play an essential role in maintaining the life cycle and disseminating the infection. Clinical disease primarily results from damage caused by the adult worms in the lymphatic vessels. The common clinical manifestations (e.g. acute filarial fever, lymphoedema, elephantiasis, hydrocele) can incur considerable incapacity to the affected individuals, with consequent loss of income and social and psychological stress, and LF has been recognized a leading cause of long-term disability in the world [3].

A large Global Programme to Eliminate Lymphatic Filariasis (GPELF), launched in 2000 by the World Health Organization, has targeted LF for elimination [4]. The GPELF provides guidance and support to national control programmes. The principal intervention measure recommended by GPELF is annual mass drug administration (MDA) of two-drug combinations to LF endemic communities. In most endemic countries a combination of diethylcarbamazine (DEC) and albendazole is used, but due to the risk of serious adverse reactions in individuals infected with Onchocerca volvulus, a combination of ivermectin and albendazole is used in African countries which are co-endemic for onchocerciasis. The drugs are primarily microfilaricidal and the MDAs rarely completely clear the $W$. bancrofti infection from the treated individuals. However, it is the strategy that the reduction in microfilarial load in the endemic population will lead to a simultaneous reduction of transmission, and that the MDAs thereby will prevent new infections to establish. With time the already established infections will also die out and LF will be eliminated. The term "transmission control" has been adopted for this strategy.

In Tanzania, with an estimated 34 million people at risk and 6 million people affected [5], a National Lymphatic Filariasis Elimination Programme (NLFEP) was established and began operations in 2000. The main strategy of the programme is to apply annual MDAs with a combination of ivermectin (150-200 $\mu \mathrm{g} / \mathrm{kg})$ and albendazole (400 mg) to individuals aged 5 years and above in selected programme areas. Tanga Region, located in the north-eastern part of Tanzania bordering the Indian Ocean, was enrolled in the NLFEP, and endemic areas received the first MDA, in October 2004. A study to monitor the effect of the programme was initiated before the onset of the MDAs in order to obtain baseline data on infection and transmission and to subsequently monitor the effect of control. We have previously reported from the early part of this study, namely from a community-based part carried out in the highly endemic village of Kirare [6], and from a schoolbased part assessing the effect in young pupils from 10 rural primary schools [7]. Here we report on the effect of six rounds of MDA from both the community-based and the school-based part of the study.

\section{Methods}

\section{Study sites}

All study sites were located in rural areas of Tanga District in Tanga Region, north-eastern Tanzania. The study had two parts, a community based and a school based (Figure 1). The community part was primarily carried out in Kirare village $\left(5^{\circ} 15^{\prime} 01^{\prime \prime} \mathrm{S}, 39^{\circ} 01^{\prime} 40^{\prime \prime} \mathrm{E}\right)$ located about $20 \mathrm{~km}$ south of Tanga city along the Tanga-Pangani road. In 2010, two other villages were included, namely

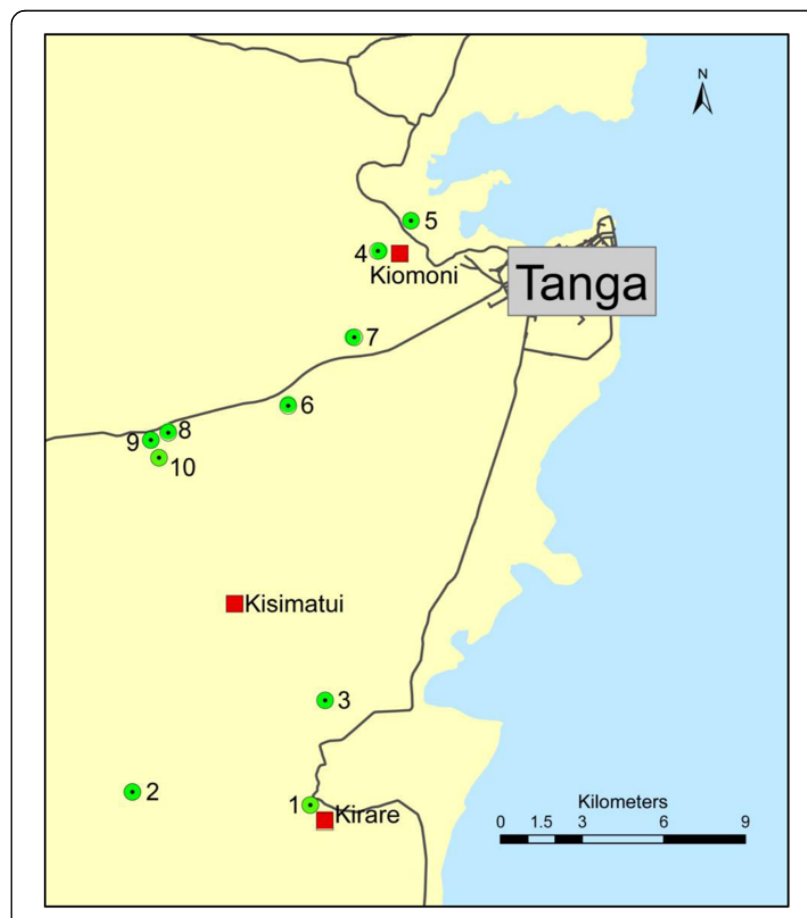

Figure 1 Map of study area showing location of the three villages (Kirare, Kiomoni and Kisimatui) and ten schools.

Schools: 1. Kirare, 2. Mapojoni, 3. Marungu, 4. Kiomoni, 5. Mafuriko, 6. Maweni, 7. Kange, 8. Pongwe, 9. Kigandini, and 10. Ziwani. 
Kiomoni (504'01" S, 3903'17" E) located about $5 \mathrm{~km}$ north-west of Tanga city near the Tanga-Amboni road, and Kisimatui ( $5^{\circ} 11^{\prime} 0^{\prime \prime}$ S, 39 $9^{\circ} 0^{\prime \prime}$ E) located about $17 \mathrm{~km}$ south-west of Tanga city along the Pongwe-Marungu road. The school part was carried out in ten rural primary schools located to the south-west (Kirare, Mapojoni and Marungu; no. 1-3), north-west (Kiomoni and Mafuriko; no. 4-5), close west (Maweni and Kange; no. 6-7) and more distant west (Pongwe, Kigandini and Ziwani; no. 8-10) of Tanga city. The distance from the schools to the centre of Tanga city ranged from 5 to $24 \mathrm{~km}$.

\section{MDA for LF control in the study area}

The Tanzanian National Lymphatic Filariasis Elimination Programme (NLFEP) administered the first three rounds of MDA in Tanga District in October 2004, February 2006 and May 2007, as reported [6]. This was followed by three additional rounds in February 2009, November 2009 and December 2010 (Table 1). The six MDAs were thus administered with time intervals of 16, 15, 21, 9 and 13 months.

\section{Design of community study}

Entomological surveillance started in Kirare in November 2003 , i.e. about one year before the first MDA, and continued uninterrupted until the end of the present reporting period.

Cross sectional community surveys for filarial infection (microfilaraemia, circulating filarial antigenemia and antibodies to $\mathrm{Bm} 14$ ) and clinical manifestations were carried out in Kirare immediately before the first MDA (September 2004; survey 1). It was intended to make similar follow-up surveys for infection shortly before each of the following MDAs, but due to irregularities in timing of the MDAs this plan could sometimes not be adhered to (Table 1). Follow-up surveys were thus carried out in January 2006, January 2007, October 2007, October 2008, October 2009, November 2010 and November 2011 (survey 2-8). Surveys 1-6 were based on a census made by the project in 2004 (updated for survey 6 by removing dead and immigrated individuals). These surveys were carried out as previously described [6], i.e. all individuals were examined for $\mathrm{mf}$ during night-time and individuals living in the 50 mosquito collection houses had a venous blood sample taken for determination of circulating filarial antigenemia and antibodies to Bm14 by ELISA (no venous samples in survey 6).

In the following two surveys (7 and 8) several changes were introduced (Table 1). First, only two of the four hamlets comprising Kirare village (Mtambuuni and Mashine) were included, as growing study-fatigue was faced in the other two hamlets (Korosini and Tundaua). As substitutes, and in order to also cover a larger geographical area, one hamlet from each of two other rural villages in Tanga District (Mabavu hamlet in Kiomoni village, and Majengo hamlet in Kisimatui village), which each had approximately the same population size as the remaining part of Kirare, were included. Second, a new census was made in all three villages in 2010 as a basis for the surveys. Third, instead of screening all individuals for mf during night-time, all

Table 1 Timing of mass drug administration (MDA) and major village and school survey activities

\begin{tabular}{lll}
\hline MDA & Village surveys & School surveys \\
\hline Oct-04: MDA1 & Sep-04: Survey 1, in hamlets 1, 2, 3 and 4 (mf, clin, Og4C3, Bm14) & Sep-04: Survey 1 (ICT) \\
\hline Jeb-06: MDA2 & Sep-05: Survey 2 (ICT) \\
\hline & Jan-07: Survey 3, in hamlets 1, 2, 3 and 4 (mf, Og4C3, Bm14) & Oct-06: Survey 3 (ICT) \\
\hline May-07: MDA3 & Oct-07: Survey 4, in hamlets 1, 2, 3 and 4 (mf, Og4C3, Bm14) & Oct-07: Survey 4 (ICT) \\
\hline Oct-08: Survey 5, in hamlets 1, 2, 3 and 4 (mf, Og4C3, Bm14) & Oct-08: Survey 5 (ICT) \\
\hline Feb-09: MDA4 & Oct-09: Survey 6, in hamlets 1, 2, 3 and 4 (mf) & Oct-09: Survey 6 (ICT) \\
\hline Nov-09: MDA5 & Nov-10: Survey 7, in hamlets 1, 2, 5 and 6 (ICT, mf) & Nov-10: Survey 7 (ICT, Bm14) \\
\hline Dec-10: MDA6 & Nov-11: Survey 8, in hamlets 1, 2, 5 and 6 (ICT, mf, Bm14) & Dec-11: Survey 8 (ICT, Bm14)
\end{tabular}

Hamlets 1, 2, 3 and 4 were in Kirare village, hamlet 5 in Kiomoni village and hamlet 6 in Kisimatui village. Types of examinations: mf $=$ microfilariae; clin = chronic clinical manifestations; Og4C3 = circulating filarial antigens by TropBio Og4C3 ELISA; ICT = circulating filarial antigens by ICT cards; Bm14 = antibodies to recombinant Bm14 antigen (by in-house ELISA during village surveys 1-5; by CELISA from Cellabs during surveys 7 and 8 ). In addition to listed activities, entomological surveillance was carried out in Kirare village continuously, and questionnaire surveys for MDA coverage was carried out in all communities and schools shortly after each MDA (the post-MDA 5 and 6 questionnaires in communities also assessed for possession of bed nets). A population census covering hamlets included in subsequent surveys was done in 2004 (before Survey 1) and 2010 (before Survey 7). Impregnated bed nets were distributed to every household in the study area in September 2011. 
individuals were first screened for CFA with rapid test cards during the day, and only those positive for CFA were screened for $\mathrm{mf}$ at night. Fourth, no venous blood samples were collected. Instead, blood spots were collected on filter paper disks during survey 8 (for later screening for antibodies to Bm14) from children aged 5-14 years immediately after the CFA testing.

\section{Design of school study}

The new Standard 1 pupils from ten selected primary schools were examined for CFA in the late part of each year, as previously described [7]. On agreed days and by following the school registers, the pupils were examined for CFA by use of rapid test cards. In 2010 and 2011, finger-prick blood was moreover collected on filter paper disks immediately thereafter (in Kirare, Marungu, Kiomoni and Mafuriko schools only), for later screening for antibodies to Bm14 (Table 1).

\section{Ethical considerations}

Meetings were held regularly in the study communities to inform the inhabitants about the study contents and findings and to obtain their cooperation. Prior to any examination, the individuals were asked if the purpose and consequences as explained during the meetings had been understood, questions for clarification were answered, and written consent to participate (from adults, and from parents or guardians of individuals less than 15 years old) was obtained.

Prior to each years' school surveys, meetings were held with the head teacher, the relevant teachers and the parents committee for the individual schools, to explain the contents and consequences of the study. The members of the parents committee provided written informed consent, on behalf on the children and their parents. Children who refused to participate in the examinations were not included.

Ethical and research clearance for the study was provided by the Medical Research Coordinating Committee of the National Institute for Medical Research, Tanzania, and the study protocol was reviewed by the Central Scientific Ethical Committee in Denmark.

\section{Test for microfilariae}

Blood was examined for $\mathrm{mf}$ by use of the counting chamber technique [8]. Sampling started at 21.00 hours. From each individual, $100 \mu \mathrm{l}$ of finger prick blood was collected in a heparinized capillary tube and transferred to a tube with $900 \mu \mathrm{l}$ of $3 \%$ acetic acid. Later in the laboratory, specimens were transferred to a counting chamber and examined for mf under a compound microscope. The specimens were examined blindly by two different technicians, and the mean count was recorded as the $\mathrm{mf}$ intensity.
Tests for circulating filarial antigens and antibodies to Bm14 During community surveys $1-5$, venous blood samples were collected from volunteers from the mosquito collection houses in Kirare, and serum was prepared and examined for circulating filarial antigens (CFA) by the TropBio Og4C3 ELISA and for antibodies to the recombinant filarial antigen Bm14 by an in-house ELISA as previously reported [6].

During community surveys 7-8, and during all school surveys, individuals were screened for CFA by use of rapid immunochromatographic test cards (ICT cards, Binax Now ${ }^{\oplus}$, Inverness Medical Innovations Inc., USA). One hundred microliters of finger-prick blood were applied to the sample pad on the test card, and the result was read after exactly 10 minutes as either positive or negative.

During community survey 8 , and during school surveys 7 and 8, finger-prick blood was moreover collected on filter paper collection disks (TropBio Pty. Ltd., Townsville, Australia) from some individuals for later detection of antibodies to Bm14. Each protrusion on the disk was saturated with blood from one individual. The disks were dried overnight, placed individually in plastic bags and frozen at $-20^{\circ} \mathrm{C}$ until use. Elution of the dried blood samples and subsequent determination of antibodies to Bm14 was done by use of the Filariasis CELISA test kit (Cellabs Pty Ltd, Brookvale, Australia). The test was performed according to the procedure from the manufacturer and as described elsewhere $[9,10]$. Each sample was tested in duplicate and the mean OD-value was recorded as the individuals' result. Individuals with OD-values $\geq$ 0.40 were considered antibody positive.

\section{Entomological surveillance}

Vector mosquitoes were collected from 50 originally randomly selected village houses using Centre for Disease Control light traps (John W. Hock Company, Gainesville, USA) hung beside an occupied, untreated bed-net [6]. A few houses were changed over the years, either because inhabitants refused continued trapping in their house or because they moved away from the village and left the house to collapse, and in these cases a neighbouring house was used instead. Traps were switched on at 1900 hours and off at 0600 hours by trained field assistants. Caught mosquitoes were transferred to paper cups and transported to the laboratory in Tanga for identification using morphological criteria. The live female vectors (An. gambiae, $A n$. funestus and $C x$. quinquefasciatus) were dissected under microscope for larvae of W. bancrofti.

\section{Assessment of treatment coverage and bed net use}

Three different methods were used to assess the treatment coverage. First, the official programme coverage for Tanga District was obtained from the regional office of the NLFEP in Tanga. According to the programme, these "reported 
coverages" were calculated as the number of treatments delivered divided by the eligible population (estimated as $80 \%$ of the total population). In addition, a "surveyed community coverage" and a "surveyed school coverage" was obtained from questionnaire surveys carried out among the inhabitants from the study communities and the Standard 1 pupils from the study schools, respectively, shortly after each MDA. In these surveys, individuals were asked in privacy whether or not they had taken the drugs that had been distributed for LF elimination (in communities, parents answered on behalf of their children below 15 years of age).

Only few houses in Kirare possessed bed nets at the start of the study in 2003, but nets were observed to gradually become more common. During the post-MDA 5 and 6 community questionnaire surveys for MDA coverage, individuals aged $\geq 15$ years were therefore also asked about the number and type of bed nets possessed in their household (was checked by visual inspection when inhabitants allowed), and the number of individuals $\geq 1$ year sleeping in the household. After MDA 5, net coverages were $27.6 \%$ (366 nets/1326 individuals) for any kind of net and 6.6\% (87/1326) for insecticide treated nets in Kirare (all four hamlets). After MDA 6, these net coverages were $27.0 \%(452 / 1674)$ and $7.1 \%$ $(118 / 1674)$, respectively, for the study hamlets of Kirare, Kiomoni and Kisimatui combined. Insecticide impregnated bed nets were distributed to every household in Tanga District in September 2011, shortly before completion of the present study.

\section{Data analysis}

Mf intensities were adjusted for sampling time by multiplying with a time-specific factor, as previously described [11]. Geometric mean intensities (GMIs) of microfilaraemia, CFA intensities and Bm14 OD-values were calculated as antilog $[(\Sigma \log \mathrm{x}+1) / \mathrm{n}]-1$, with $\mathrm{x}$ being the $\mathrm{mf} / \mathrm{ml}$, CFA units or OD-values, respectively, and $n$ the number of individuals examined.

During community surveys 7 and 8 , when only CFA positive individuals were examined for $\mathrm{mf}$, the community $\mathrm{mf}$ prevalence was calculated as: $(\mathrm{b} / \mathrm{a}) \times(\mathrm{d} / \mathrm{c}) \times 100$, where $\mathrm{a}=$ number of individuals in the community examined for CFA, $b=$ number of those examined for CFA being positive, $\mathrm{c}=$ number of CFA positives examined for $\mathrm{mf}$, and $\mathrm{d}=$ number of those examined for $\mathrm{mf}$ being positive. In these surveys, the community $\mathrm{mf}$ GMI was calculated as antilog $\left[\left(\sum \log \mathrm{x}+1\right) /(\mathrm{c} / \mathrm{b} \times \mathrm{a})\right]-1$, with $\mathrm{x}$ being the $\mathrm{mf} / \mathrm{ml}$ and $(\mathrm{c} / \mathrm{b} \times \mathrm{a})$ being the number of individuals examined (taking into account that sometimes not all CFA positive individuals were examined for $\mathrm{mf}$ ).

Entomological indices for vector biting and transmission were calculated as previously described [12]. Briefly, the monthly biting rate (MBR; a measure of the number of mosquito bites per person in the month) was calculated as: (total mosquito catch $\times$ days in month $\times 3$ )/(number of catching nights $\times$ number of light traps $\times 2$ ). The monthly transmission potential (MTP; a measure of the number of infective larvae to which a person is exposed in the month) was calculated as: (MBR $\times$ total number of infective larvae seen in the dissections)/(number of mosquitoes dissected). The "infectivity rate" was calculated as the percent of mosquitoes infected with infective larvae (L3) and the "infection rate" as the percent of mosquitoes infected with any stage of the parasite (L1, L2 and/or L3).

\section{Results}

\section{Lymphatic filariasis in Kirare before treatment}

Table 2 gives an overview of the LF infection and disease status in the human population of Kirare as seen during the pre-MDA survey in September 2004. The population was heavily affected, with community prevalence rates of $24.5 \%, 53.3 \%$ and $78.9 \%$ for mf, CFA and filarial (Bm14) specific antibodies, respectively. $4.1 \%$ of the adults ( $\geq 20$ years) had elephantiasis and $32.8 \%$ of the adult males had hydrocele. Statistical comparison of the LF status in the overall population of Kirare (all four hamlets) to that in the village section included in the later part of the study (Mtambuuni and Mashine hamlets only) indicated no significant differences.

Dissection of mosquitoes caught from the 50 collection houses during the 11 months pre-MDA period indicated that the area had three species of vectors (Table 3), and that these had a combined mean MBR of 174.3 and mean MTP of 6.1 (Figure 2). An. funestus was the most abundant (mean MBR of 71.3) and contributed most to transmission (mean MTP of 3.5) followed by An. gambiae (49.3 and 1.9, respectively) and $C x$. quinquefasciatus (53.6 and 0.7, respectively). Vector biting and transmission varied by season (Figure 3), and generally was most pronounced during and after the rainy seasons (November-December and April-June).

\section{Effect of MDAs on $\mathrm{mf}$ in community surveys}

In the early part of the study (survey 1-6), all individuals in Kirare were examined for $\mathrm{mf}$. The $\mathrm{mf}$ prevalence and $\mathrm{mf}$ GMI for all 4 hamlets combined in survey 1-5 were presented previously [6]. Following an initial steep and statistically significant decrease in $\mathrm{mf}$ prevalence and $\mathrm{mf}$ GMI after each of the first three MDAs there was a levelling out of the effect between survey 4 and 5 , probably because of the extended delay of MDA 4. In survey 6 (survey population: 1029; number examined: 477), the $\mathrm{mf}$ prevalence and $\mathrm{mf}$ GMI decreased to $5.5 \%$ and 0.34 $\mathrm{mf} / \mathrm{ml}$ (from $10.6 \%$ and $0.75 \mathrm{mf} / \mathrm{ml}$ during survey 5 ), respectively. When tested for individuals included in both surveys these decreases were statistically significant ( $n=262$; McNemar's chi-square test for paired samples, 
Table 2 Overview of the LF status in Kirare, as seen in the pre-MDA survey in September 2004

\begin{tabular}{|c|c|c|c|}
\hline Characteristic & Kirare village (all 4 hamlets) & Mtambuuni and Mashine hamlets & p-value $\left(x^{2}\right.$-test $)$ \\
\hline Registered population $\geq 1 \mathrm{yr}$ & 1112 & 530 & - \\
\hline Examined population $\geq 1 \mathrm{yr}$ & 919 & 471 & - \\
\hline Male : female ratio among examined & 0.88 & 0.85 & 0.76 \\
\hline Proportion of examined below 20 yrs & $53.0 \%$ & $48.4 \%$ & 0.11 \\
\hline Mf prevalence & $24.5 \%$ & $26.1 \%$ & 0.51 \\
\hline Mf GMI* among all examined & 4.11 & 4.83 & - \\
\hline Mf GMI* among mf positive & 781.3 & 851.1 & - \\
\hline CFA prevalence ${ }^{\#}$ & $53.3 \%$ & $54.7 \%$ & 0.87 \\
\hline Bm14 prevalence ${ }^{\#}$ & $78.9 \%$ & $78.1 \%$ & 0.91 \\
\hline Hydrocele prevalence (in males $\geq 20 \mathrm{yrs})^{\S}$ & $35.4 \%$ & $45.2 \%$ & 0.11 \\
\hline Elephantiasis prevalence (in all $\geq 20 \mathrm{yrs})^{\S}$ & $4.2 \%$ & $5.8 \%$ & 0.35 \\
\hline
\end{tabular}

Shown for the complete village (Mtambuuni, Korosini, Mashine and Tundaua hamlets) and for the village section included in the later part of the study (Mtambuuni and Mashine hamlets only).

* Geometric mean intensity, in $\mathrm{mf} / \mathrm{ml}$ blood.

\# Based on volunteers from mosquito collection houses only (90 and 64 examined individuals from the four and two hamlets of Kirare, respectively).

${ }^{\S}$ Assessed in 175 and 104 males (hydrocele), and in 431 and 242 males and females (elephantiasis), in the four and two hamlets of Kirare, respectively.

Table 3 Vector mosquito catches from the $\mathbf{5 0}$ collection houses in Kirare and the outcome of dissections

\begin{tabular}{|c|c|c|c|c|}
\hline & Total & An. gambiae & An. funestus & Cx. quinquefasciatus \\
\hline \multicolumn{5}{|l|}{ Pre-MDA period (11 months)* } \\
\hline No. mosquitoes caught & 8346 & 2335 & 3385 & 2626 \\
\hline No. mosquitoes dissected & 5396 & 1477 & 2080 & 1839 \\
\hline No. with infection (\% of dissected ${ }^{\#}$ ) & $187(3.47)$ & $56(3.79)$ & $94(4.52)$ & $37(2.01)$ \\
\hline No. with L3 (\% of dissected ${ }^{\S}$ ) & $77(1.43)$ & $20(1.35)$ & $48(2.31)$ & $9(0.49)$ \\
\hline No. of $L 3$ & 153 & 51 & 87 & 15 \\
\hline \multicolumn{5}{|l|}{ Post-MDA period $4\left(9\right.$ months) ${ }^{* *}$} \\
\hline No. mosquitoes caught & 1930 & 7 & 5 & 1918 \\
\hline No. mosquitoes dissected & 1830 & 5 & 4 & 1821 \\
\hline No. with infection (\% of dissected ${ }^{\#}$ ) & $6(0.33)$ & $0(0.00)$ & $0(0.00)$ & $6(0.33)$ \\
\hline No. with L3 (\% of dissected $\left.{ }^{\S}\right)$ & $1(0.05)$ & $0(0.00)$ & $0(0.00)$ & $1(0.05)$ \\
\hline No. of L3 & 3 & 0 & 0 & 3 \\
\hline \multicolumn{5}{|l|}{ Post-MDA period 5 (13 months) ${ }^{* * *}$} \\
\hline No. mosquitoes caught & 5148 & 119 & 27 & 5002 \\
\hline No. mosquitoes dissected & 3976 & 71 & 23 & 3882 \\
\hline No. with infection (\% of dissected ${ }^{\#}$ ) & $9(0.23)$ & $0(0.00)$ & $0(0.00)$ & $9(0.23)$ \\
\hline No. with $L 3$ (\% of dissected ${ }^{\S}$ ) & $4(0.10)$ & $0(0.00)$ & $0(0.00)$ & $4(0.10)$ \\
\hline No. of L3 & 4 & 0 & 0 & 5 \\
\hline \multicolumn{5}{|l|}{ Post-MDA period 6 (12 months) $)^{* * * *}$} \\
\hline No. mosquitoes caught & 8982 & 416 & 74 & 8492 \\
\hline No. mosquitoes dissected & 7713 & 387 & 74 & 7252 \\
\hline No. with infection (\% of dissected") & $2(0.03)$ & $0(0.00)$ & $0(0.00)$ & $2(0.03)$ \\
\hline No. with L3 (\% of dissected ${ }^{\S}$ ) & $1(0.01)$ & $0(0.00)$ & $0(0.00)$ & $1(0.01)$ \\
\hline No. of L3 & 2 & 0 & 0 & 2 \\
\hline
\end{tabular}

Results shown are from the pre-MDA period and post-MDA periods 4-6. Results from post-MDA periods 1-3 are given in [6].

* Nov-03 to Sep-04; ** Feb-09 to Oct-09; *** Nov-09 to Nov-10; **** Dec-10 to Nov-11.

\# Infection rate.

$\S$ Infectivity rate. 

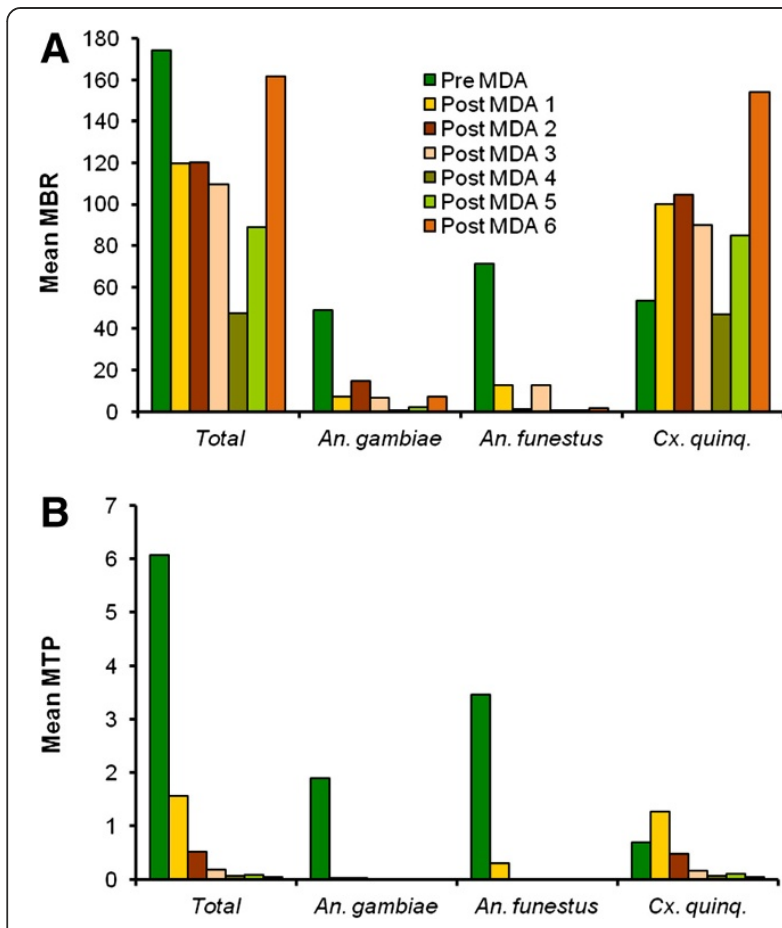

Figure 2 Vector-biting and transmission in the pre-MDA period and the six post-MDA periods in Kirare. A shows mean monthly biting rate (MBR) and $\mathbf{B}$ shows mean monthly transmission potential (MTP)

$\mathrm{p}=0.02$ and paired $t$-test, $\mathrm{p}=0.03$, respectively). Thus, there was a general trend of a continued and statistically significant decrease in microfilaraemia as long as the spacing of MDAs did not become too long. The prevalence for all hamlets of Kirare combined in survey 1-6 are shown in Figure 4.

When looking at the two hamlets of Kirare which were also examined in the later part of the study (Table 4 and Figure 4), the $\mathrm{mf}$ prevalence and $\mathrm{mf}$ GMI during the first six surveys followed the trend seen for all four hamlets combined. Thus, after each of the first three MDAs the $\mathrm{mf}$ prevalence decreased progressively and statistically significantly $(\mathrm{n}=421,395$ and 329; $\mathrm{p}<0.001, \mathrm{p}=0.01$ and $\mathrm{p}<0.001$, McNemar's test), from $26.1 \%$ in the preMDA survey to $10.0 \%$ in survey 4 . This was followed by a non-significant increase to $12.9 \%$ in survey 5 (probably due to the prolonged period without treatment) and a significant decrease to $5.0 \%$ in survey $6(n=254$ and $160 ; \mathrm{p}=0.19$ and $\mathrm{p}=0.013$, McNemar's test). The mf prevalence continued its downward move to $4.4 \%$ and $2.7 \%$ in survey 7 and 8 , respectively (statistics cannot be computed due to the method used for assessing $\mathrm{mf}$ prevalence in these surveys, see Methods and Table 4). The community $\mathrm{mf}$ GMI followed a similar trend, with significant decrease after each MDA from pre-MDA survey to survey 4 , then a slight but non-significant increase in survey 5 , followed by a significant decrease in survey $6(\mathrm{p}<0.001, \mathrm{p}<0.001$, $\mathrm{p}=0.005, \mathrm{p}=0.13$ and $\mathrm{p}=0.039$; paired $t$-test). In the following two surveys the community $\mathrm{mf}$ GMI continued to decrease to 0.25 and $0.16 \mathrm{mf} / \mathrm{ml}$, respectively (again, statistics cannot be computed). When considered for $\mathrm{mf}$ positive individuals only, the mf GMIs initially decreased considerably from pre-MDA survey to survey 3 , but thereafter remained relatively high for the remaining study period, probably due to systematic non-compliance to treatment of some $\mathrm{mf}$ positive individuals.

The $\mathrm{mf}$ prevalence and $\mathrm{mf}$ GMI in Kiomoni and Kisimatui (Table 4, Figure 4) also followed a downward trend between survey 7 and 8 (statistics cannot be computed). In both surveys, these indices were considerably higher in Kisimatui than in Kiomoni and Kirare.

\section{Effect of MDAs on CFA and antibodies to Bm14 in community surveys}

In the early part of the study (survey 1-5), the effect of MDAs on CFA and antibodies to Bm14 was assessed by ELISA on serum samples from volunteers from the 50 mosquito collection houses in Kirare (see details in [6]). For CFA, a slow decrease was seen in prevalence from $53.3 \%$ in survey 1 to $44.9 \%$ in survey 5 (Figure 5), whereas a more substantial decrease was seen for the GMIs (reduction by $56 \%$ ). For antibodies to $\mathrm{Bm} 14$, a negligible decrease in prevalence was seen from $78.9 \%$ in survey 1 to $75.5 \%$ in survey 5 , whereas again a more substantial decrease was seen for the GMIs (reduction by $48 \%$ ).

In survey 7 and 8 , all individuals in the study communities were examined for CFA with ICT cards (Table 5; Figure 5). The prevalence in Kirare had decreased considerably from the $44.9 \%$ in survey 5 (all four hamlets) to $25.3 \%$ and $19.6 \%$ in survey 7 and 8 (two hamlets only), respectively. In all three villages of Kirare, Kiomoni and Kisimatui, the decrease in CFA prevalence between survey 7 and 8 was statistically significant (Table 5).

In survey 8, children aged 5-14 years from Kirare, Kiomoni and Kisimatui were examined for antibodies to Bm14 by CELISA (Table 6). The prevalence in Kirare had decreased considerably from the $75.5 \%$ in survey 5 (all four hamlets, all age groups) to $27.5 \%$ in survey 8 (two hamlets, children only), and the GMI of the CELISA OD-value was reduced by $16 \%$ (from 0.405 to 0.338 ) between these surveys. Similar levels of prevalence and OD-value GMI were seen in the three villages in survey 8 (mean of $23.0 \%$ and 0.2865 , respectively).

\section{Effect of MDAs on vectors and transmission in Kirare}

A considerable change in vector species composition was observed already in the early study period [6], from predominantly anopheline in the pre-MDA period (An. gambiae and An. funestus comprising $68.5 \%$ of the catch) to predominantly culicine in the post-MDA 3 period (Cx. quinquefasciatus comprising $82.0 \%$ of the 
Simonsen et al. BMC Infectious Diseases 2013, 13:335

Page 8 of 16

http://www.biomedcentral.com/1471-2334/13/335
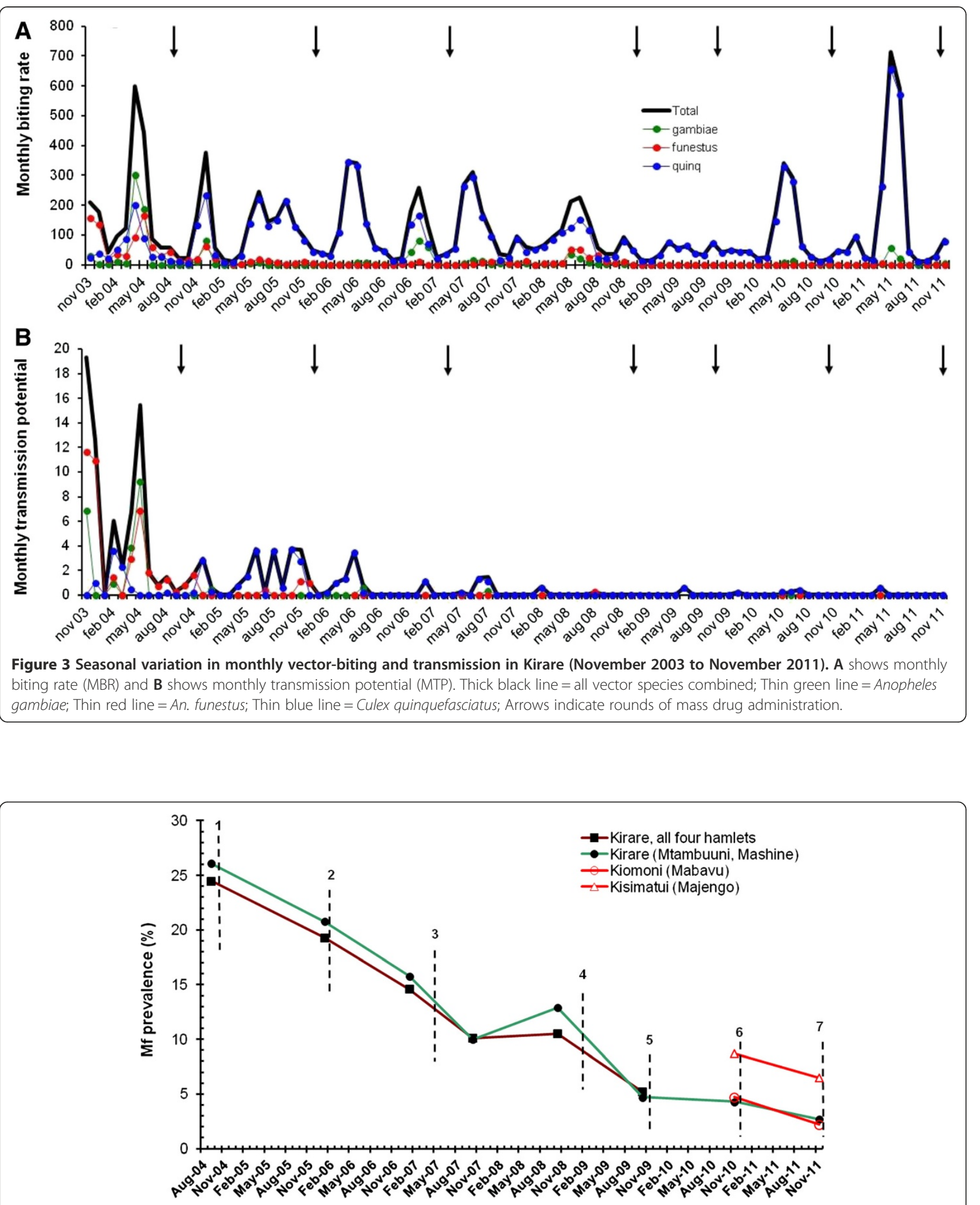

Figure 4 Effect of six rounds of mass drug administration (MDA) on Wuchereria bancroft microfilaria prevalence. Brown line = all four hamlets of Kirare in survey 1-6; Green line = two hamlets of Kirare (Mtambuuni, Machine) in survey 1-8; Red lines= one hamlet of Kiomoni (Mabavu) and one hamlet of Kisimatui (Majengo) in survey 7 and 8 . In survey 1-6 all individuals $\geq 1$ year were examined for mf. In survey 7 and 8 all individuals $\geq 1$ year were first examined for CFA, and those positive were examined for mf. Vertical stippled lines indicate rounds of MDA. 
Table 4 Microfilaraemia in the study communities

\begin{tabular}{lccccccc}
\hline Study population & Survey no. & Time of survey & Survey population & No. examined (\%) & $\begin{array}{c}\text { No. positive } \\
\text { for mf (\%) }\end{array}$ & $\begin{array}{c}\text { Mf GMI* for } \\
\text { all examined }\end{array}$ & $\begin{array}{c}\text { Mf GMI* for } \\
\text { positives }\end{array}$ \\
\hline Kirare & 1 & Sep-04 & 530 & $471(88.9)$ & $123(26.1)$ & 4.83 & 851.1 \\
& 2 & Jan-06 & 530 & $461(87.0)$ & $96(20.8)$ & 2.46 & 385.7 \\
& 3 & Jan-07 & 530 & $438(82.6)$ & $69(15.8)$ & 1.08 & 101.5 \\
& 4 & Oct-07 & 530 & $351(66.2)$ & $35(10.0)$ & 0.70 & 200.3 \\
& 5 & Oct-08 & 530 & $302(57.0)$ & $39(12.9)$ & 0.90 & 142.4 \\
& 6 & Oct-09 & 512 & $259(53.5)$ & $13(5.0)$ & 0.30 & 194.7 \\
& 7 & Nov-10 & 690 & $400(58.0)^{\#}$ & $17^{\S}(4.4)$ & $0.25^{\text {a }}$ & 178.9 \\
\hline Kiomoni & 8 & Nov-11 & 690 & $393(57.0)^{\#}$ & $11^{\S}(2.7)$ & $0.15^{\text {a }}$ & 180.8 \\
\hline Kisimatui & 7 & Nov-10 & 504 & $386(76.6)^{\#}$ & $18^{\S}(4.7)$ & $0.34^{\alpha}$ & 423.1 \\
& 8 & Nov-11 & 504 & $312(61.9)^{\#}$ & $7^{\S}(2.2)$ & $0.16^{\alpha}$ \\
\hline
\end{tabular}

Results shown are for two hamlets of Kirare (Mtambuuni, Mashine) in survey 1-8, as well as for one hamlet of Kiomoni (Mabavu) and one hamlet of Kisimatui (Majengo) in survey 7 and 8 . Results from all four hamlets of Kirare in survey 1-5 are given in [6].

* Geometric mean intensity, in $\mathrm{mf} / \mathrm{ml}$ blood.

\# Number (\%) examined for CFA. In survey 7 and 8, the "number of CFA positives/number of CFA positives examined for mf/number of mf positives detected" were 101/89/15 and 77/65/9 for Kirare, 74/68/17 and 52/52/7 for Kiomoni and 110/91/28 and 84/63/18 for Kisimatui, respectively.

${ }^{\S}$ Expected number of $\mathrm{mf}$ positives among those examined for CFA. Calculated as [number positive for CFA] $\times$ [number positive for mf] / [number CFA positives examined for $\mathrm{mf}$.

${ }^{a}$ Expected $\mathrm{mf}$ GMI among those examined for CFA. See Methods for calculation.

combined catch; $\mathrm{p}<0.001$, Pearson chi-square test). This change became even more pronounced in post-MDA period 4-6, when $C x$. quinquefasciatus comprised $95.6 \%$ of the combined catch (Table 3; $\mathrm{p}<0.001$, Pearsons chi-square test comparing post MDA period 1-3 to post MDA period 4-6). The overall mean MBR was 174.3 in the pre-MDA period (Figure 2). It decreased gradually to 47.4 in post-MDA period 4 , but thereafter increased again to 89.1 and 161.8 in post-MDA period 5 and 6, respectively, due to an increase in the culicine population. In addition to these long-term changes, there were marked seasonal fluctuations in vector species composition and abundance (Figure 3A).

When analysed for the three vector species combined, the vector infectivity rate decreased markedly and statistically significantly in the early part of the study, from $1.43 \%$

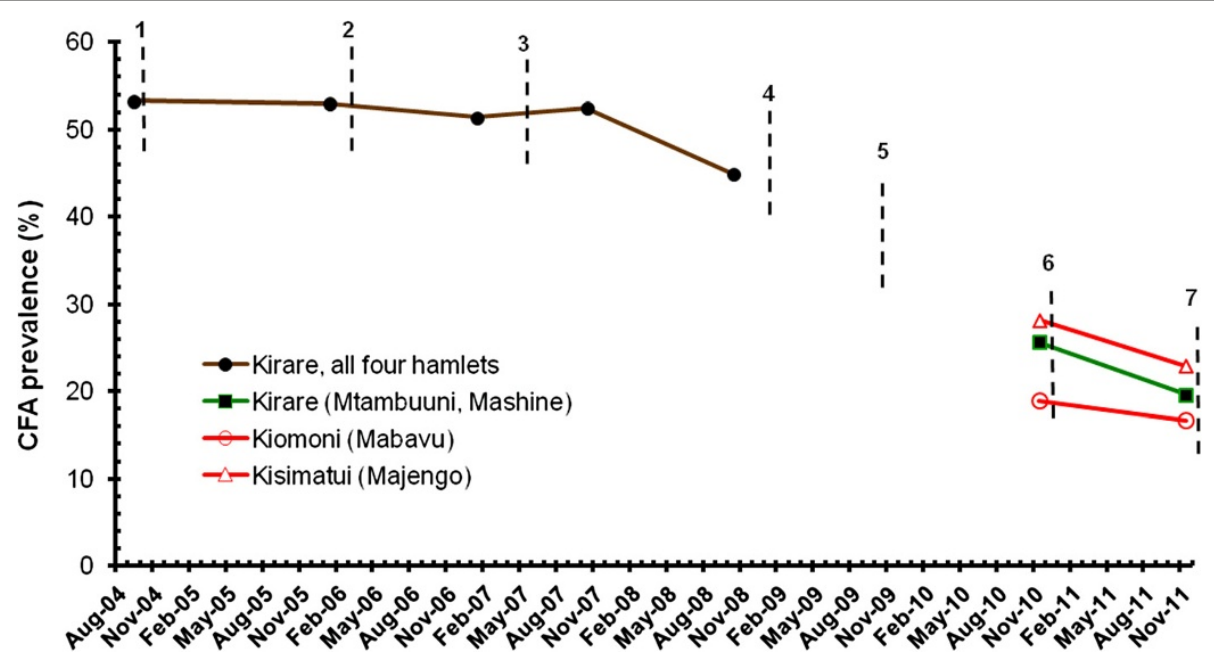

Figure 5 Effect of six rounds of mass drug administration (MDA) on circulating filarial antigen (CFA) prevalence. Brown line =volunteers from mosquito collection houses located in all four hamlets of Kirare examined for CFA by ELISA in survey 1-5. Green line $=$ all individuals $\geq 1$ year from two hamlets of Kirare (Mtambuuni, Mashine) examined for CFA by ICT cards in survey 7 and 8 . Red lines $=$ all individuals $\geq 1$ year from one hamlet of Kiomoni (Mabavu) and one hamlet of Kisimatui (Majengo) examined for CFA by ICT cards in survey 7 and 8. Vertical stippled lines indicate rounds of MDA. 
Table 5 Circulating filarial antigen (CFA) prevalence in the study communities

\begin{tabular}{|c|c|c|c|c|c|}
\hline Study population & $\begin{array}{c}\text { Time (number) } \\
\text { of survey }\end{array}$ & $\begin{array}{c}\text { Survey } \\
\text { population }\end{array}$ & No. examined (\%) & No. positive (\%) & $\begin{array}{l}\text { p-value for difference } \\
\text { in prevalence }\end{array}$ \\
\hline \multirow[t]{2}{*}{ Kirare } & Nov-10 (7) & 690 & $400(58.0)$ & $101(25.3)$ & $0.044^{*}$ \\
\hline & Nov-11 (8) & 690 & $393(57.0)$ & 77 (19.6) & \\
\hline \multirow[t]{2}{*}{ Kiomoni } & Nov-10 (7) & 504 & $386(76.6)$ & $74(19.2)$ & $0.041^{*}$ \\
\hline & Nov-11 (8) & 504 & $312(61.9)$ & $52(16.7)$ & \\
\hline \multirow[t]{2}{*}{ Kisimatui } & Nov-10 (7) & 651 & $389(59.8)$ & $110(28.3)$ & $0.001^{*}$ \\
\hline & Nov-11 (8) & 651 & $367(56.4)$ & $84(22.9)$ & \\
\hline \multirow[t]{2}{*}{ All 3 communities combined } & Nov-10 (7) & 1845 & $1175(63.7)$ & $285(24.3)$ & $<0.001^{\#}$ \\
\hline & Nov-11 (8) & 1845 & $1072(58.1)$ & $213(19.9)$ & \\
\hline
\end{tabular}

Results shown are from two hamlets of Kirare (Mtambuuni, Mashine), one hamlet of Kiomoni (Mabavu) and one hamlet of Kisimatui (Majengo) in survey 7 and 8. Results from all four hamlets of Kirare in survey 1-5 are given in [6] and in Figure 3.

* McNemar's chi-square test for paired samples ( $n=318,289,297$ and 904 for Kirare, Kiomoni, Kisimatui and all three villages combined, respectively).

\# Pearsons chi-square test.

in the pre-MDA period to $0.10 \%$ in the post-MDA 3 period $(p<0.001$, chi-square test; see also [6]). The vector infectivity rate decreased further after subsequent MDAs, to $0.05 \%$ and $0.01 \%$ in post-MDA periods 4 and 6 (Table 3), respectively, although changes from post-MDA 3 period and onwards did not reach statistical significance due to the low number of infective vectors relative to the number of vectors dissected. The downward trend in infectivity rate was seen for all three vector species. However, whereas no infective larvae were seen in the two anopheline species in post-MDA period 4, 5 and 6 (very few anophelines were caught), infective $C x$. quinquefasciatus were recovered in all periods (Figure 3B, Table 3). The decrease in vector infectivity rates resulted in progressively less $W$. bancrofti transmission (Figure 2). Thus, the overall mean MTP decreased from 6.08 in the preMDA period to $1.56,0.53,0.19,0.07,0.08$ and 0.05 in post-MDA period 2, 3, 4, 5 and 6, respectively (reductions by $74.3 \%, 91.3 \%, 96.9 \%, 98.8 \%, 98.7 \%$ and $99.2 \%$, respectively, in relation to the pre-MDA value). Meanwhile $C x$. quinquefasciatus gradually became responsible for more and more of the transmission, and in the last three post-MDA periods this species was the only observed vector.

\section{Effect of MDA in school surveys}

Approximately 800 new Standard 1 pupils from the 10 study schools were examined each year shortly after enrolling in school. The overall CFA prevalence was $25.2 \%$ in the pre-MDA survey (Table 7; Figure 6). The prevalence showed only minor and non-significant change to $23.6 \%$ and $23.3 \%$ in survey 2 and 3, respectively. This was followed by more substantial and statistically significant decreases to $12.5 \%, 9.7 \%$ and $6.4 \%$ during the next three surveys (see also [7]). The decrease thereafter levelled off, and prevalences reached $6.1 \%$ and $5.6 \%$ in survey 7 and 8 . When comparing these prevalences to those seen one year earlier, or comparing the prevalence in survey 6 to that in survey 8 , the differences were not statistically significant $(\mathrm{p}=0.80,0.65$ and 0.48 , respectively, Pearsons chi-square test). Similar trends

Table 6 Antibodies to Bm14 in children from the study communities and the study schools

\begin{tabular}{|c|c|c|c|c|c|c|c|}
\hline & Study population & $\begin{array}{c}\text { Time (number) } \\
\text { of survey }\end{array}$ & $\begin{array}{c}\text { Survey } \\
\text { population }\end{array}$ & $\begin{array}{c}\text { No. examined } \\
(\%)\end{array}$ & $\begin{array}{c}\text { Mean age } \\
\text { years }\end{array}$ & $\begin{array}{l}\text { No. positive } \\
(\%)\end{array}$ & $\begin{array}{l}\text { GMI* for all } \\
\text { examined }\end{array}$ \\
\hline \multirow[t]{4}{*}{ Community surveys } & Kirare & Nov-11 (8) & 178 & $120(67.4)$ & 10.1 & $33(27.5)$ & 0.3384 \\
\hline & Kiomoni & Nov-11 (8) & 145 & $107(73.8)$ & 9.9 & $24(22.4)$ & 0.2776 \\
\hline & Kisimatui & Nov-11 (8) & 180 & $129(71.7)$ & 9.4 & $25(19.4)$ & 0.2468 \\
\hline & All 3 communities combined & Nov-11 (8) & 503 & $356(70.8)$ & 9.8 & $82(23.0)$ & 0.2865 \\
\hline \multirow[t]{2}{*}{ School surveys } & All 4 schools combined & Nov-10 (7) & 453 & $362(79.9)$ & 7.4 & $61(16.9)^{\#}$ & $0.2776^{\S}$ \\
\hline & & Dec-11 (8) & 382 & $334(87.3)$ & 7.2 & $38(11.4)^{\#}$ & $0.2153^{\S}$ \\
\hline
\end{tabular}

Results shown are from children (5-14 years) from two hamlets of Kirare (Mtambuuni, Mashine), one hamlet of Kiomoni (Mabavu) and one hamlet of Kisimatui (Majengo) in community survey 8 , and from Standard 1 children from four of the study schools (Kirare, Marungu, Kiomoni and Mafuriko) in survey 7 and 8. Findings from survey 1-5 in Kirare (all four hamlets) are given in [6].

* Geometric mean intensity, in OD-values.

\# $p=0.039$ (Pearsons chi-square test).

${ }_{\S} \mathrm{p}=0.032$ (independent sample $t$-test on log-transformed OD-values). 
Table 7 Circulating filarial antigen (CFA) prevalence in Standard 1 pupils from the 10 primary schools

\begin{tabular}{lcccccc}
\hline $\begin{array}{l}\text { Time (number) } \\
\text { of survey }\end{array}$ & $\begin{array}{c}\text { No. pupils } \\
\text { registered }\end{array}$ & $\begin{array}{c}\text { No. examined } \\
\text { (\% of registered) }\end{array}$ & $\begin{array}{c}\text { No. girls/boys } \\
\text { (ratio)* }\end{array}$ & $\begin{array}{c}\text { Mean age in } \\
\text { years (range) }\end{array}$ & $\begin{array}{c}\text { No. positive for CFA } \\
\text { (\% of examined) }\end{array}$ & $\begin{array}{c}\text { p-value for change in CFA } \\
\text { prevalence from previous year }\end{array}$ \\
\hline Sep-04 (1) & 888 & $832(93.7)$ & $399 / 433(0.92)$ & $8.1(6-14)$ & $210(25.2)$ & - \\
Sep-05 (2) & 892 & $691(77.5)$ & $337 / 354(0.95)$ & $7.5(6-14)$ & $163(23.6)$ & 0.50 \\
Oct-06 (3) & 981 & $803(81.9)$ & $406 / 397(1.02)$ & $7.9(6-12)$ & $187(23.3)$ & 0.84 \\
Oct-07 (4) & 953 & $806(84.6)$ & $433 / 373(1.16)$ & $7.7(6-16)$ & $101(12.5)$ & $<0.001$ \\
Oct-08 (5) & 971 & $848(87.4)$ & $419 / 429(0.98)$ & $7.6(6-12)$ & $82(9.7)$ & 0.064 \\
Oct-09 (6) & 855 & $760(88.9)$ & $386 / 374(1.03)$ & $7.6(6-12)$ & $49(6.4)$ & 0.018 \\
Nov-10 (7) & 966 & $831(86.0)$ & $404 / 427(0.95)$ & $7.5(6-12)$ & $51(6.1)$ & 0.80 \\
Dec-11 (8) & 943 & $889(94.3)$ & $421 / 468(0.92)$ & $7.5(6-11)$ & $50(5.6)$ & 0.65
\end{tabular}

Each year, the new intake of Standard 1 pupils in the 10 schools (Kiomoni, Mafuriko, Marungu, Kirare, Mapojoni, Pongwe, Kigandini, Maweni, Ziwani and Kange) was examined for CFA with ICT cards.

* For examined.

\# Pearsons chi-square test.

of CFA prevalence decrease were seen in the four school clusters (Figure 6).

The Standard 1 pupils from four of the schools (Kirare, Marungu, Kiomoni and Mafuriko) were moreover examined for antibodies to Bm14 in survey 7 and 8 (Table 6). Despite the minor change in CFA prevalence between these two surveys, the Bm14 antibody response decreased significantly, both when considering prevalence of positivity (from $16.9 \%$ to $11.4 \%, \mathrm{p}=0.026$; Pearsons chi-square test) and GMI of OD-values (from 0.2776 to $0.2153, \mathrm{p}=0.032, t$-test). The slightly lower values observed in children in the school surveys compared to those in the communities (Table 6) are likely to be due to the lower mean age of the former than the later group (7.2 vs. 9.8 years in 2011).

\section{MDA treatment coverage}

The treatment coverage in MDA 1-6, as assessed by three different methods, is shown in Table 8. The official NLFEP "reported coverage" for Tanga District was very high for all MDAs, with three of the treatment rounds covering $95 \%$ or more of the eligible population. The "surveyed community coverage" obtained from interviews in the study communities was generally lower than the "reported coverage" by 7-30\% (with exception of MDA 1). The "surveyed school coverage" obtained from interviews with the Standard 1 pupils from the 10 study schools was even lower (again with exception of MDA 1), in particular during the last three MDAs where only half or less of the children reported that they had taken the treatment.

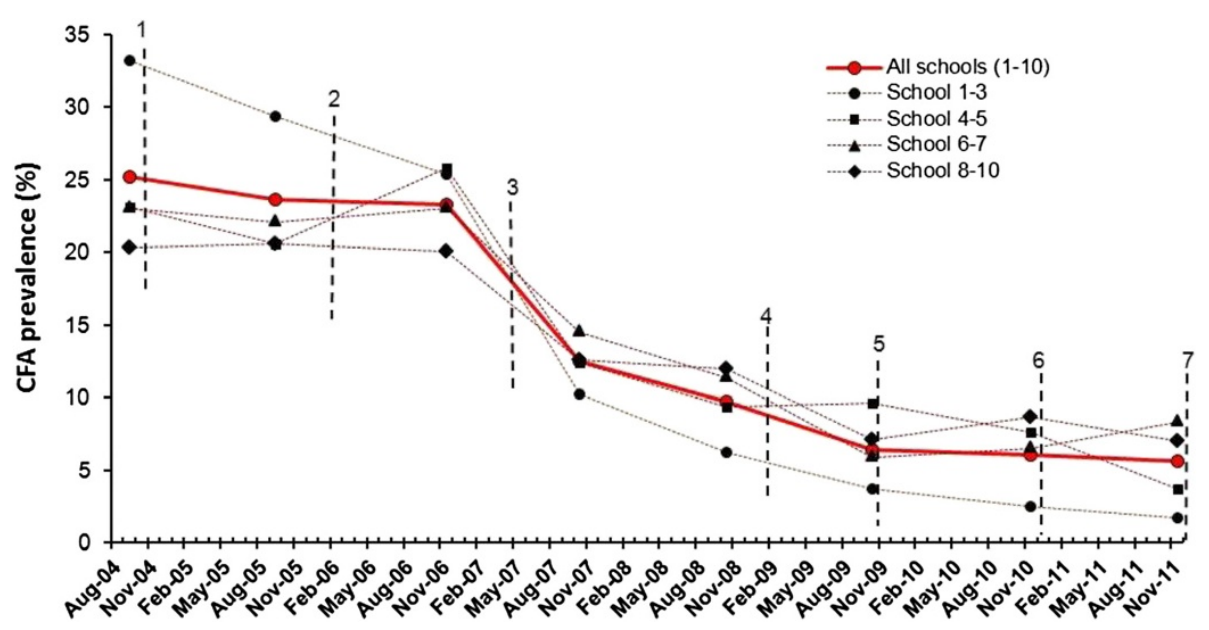

Figure 6 Effect of six rounds of mass drug administration (MDA) on circulating filarial antigen (CFA) prevalence in Standard 1 children. Thick line = prevalence for all 10 schools combined. Thin stippled lines = prevalence in school clusters according to their location to the south-west (Kirare, Mapojoni and Marungu schools; no. 1-3), north-west (Kiomoni and Mafuriko schools; no. 4-5), close west (Maweni and Kange schools; no. 6-7) and more distant west (Pongwe, Kigandini and Ziwani schools; no. 8-10) of Tanga. Vertical stippled lines indicate rounds of MDA. 


\begin{tabular}{|c|c|c|c|c|}
\hline \multirow[t]{2}{*}{ MDA no. } & \multirow{2}{*}{$\begin{array}{c}\text { Time of } \\
\text { MDA }\end{array}$} & \multirow{2}{*}{$\begin{array}{l}\text { Reported coverage } \\
\text { for the district in } \%^{*}\end{array}$} & \multicolumn{2}{|c|}{ Surveyed coverage in $\%$} \\
\hline & & & $\begin{array}{c}\text { Community } \\
\text { study }^{\#}\end{array}$ & $\begin{array}{l}\text { School } \\
\text { study }\end{array}$ \\
\hline 1 & Oct-04 & 80.0 & 82.3 & 80.0 \\
\hline 2 & Feb-06 & 95.0 & 79.0 & 68.2 \\
\hline 3 & May-07 & 87.0 & 69.9 & 61.2 \\
\hline 4 & Feb-09 & 96.6 & 66.8 & 32.9 \\
\hline 5 & Nov-09 & 98.7 & 86.4 & 43.1 \\
\hline 6 & Dec-10 & 75.0 & 67.9 & 50.3 \\
\hline
\end{tabular}

* Official NLFEP coverage for eligible individuals in Tanga District, where the three study villages and ten study schools are located.

\# Assessed by interviews shortly after each MDA in the study communities $(975,1009,883,930,778$ and 1462 individuals aged $\geq 5$ years interviewed after MDA 1-6, respectively).

${ }^{\S}$ Assessed by interviews shortly after each MDA in the 10 study schools $(859,676,776,836,704$ and 746 Standard 1 pupils interviewed after MDA $1-6$, respectively).

\section{Discussion}

Following the launching of GPELF in 2000 and the targeting of LF for global elimination, most endemic countries have established national control programmes and many are in the process of implementing annual MDAs with the recommended two-drug combinations [4]. Regular monitoring of the effect of the programmes is essential to evaluate the progress, to make evidence based adjustments and to ultimately end the MDAs when specified programme stopping criteria have been met $[13,14]$. Thorough assessments and analyses of the effect of MDAs on transmission and human infection in sentinel sites have been documented, especially from countries using the DEC/albendazole combination such as Egypt [15], Papua New Guinea [16,17], American Samoa [18,19], India [20] and Samoa [21]. Many LF endemic countries in sub-Saharan Africa are co-endemic for onchocerciasis, and due to the potential risk of DEC induced side-effects in individuals with Onchocerca volvulus infections, use a combination of ivermectin and albendazole in their MDAs for LF control. The effect of this drug combination in a low-moderate LF endemic area of central Nigeria, West Africa, was recently documented $[22,23]$. Here we present and analyse the effect of six rounds of MDA with ivermectin and albendazole in a highly endemic area of Tanzania, East Africa.

The coastal area of north-eastern Tanzania is well known to be endemic for LF, and has been a focus for comprehensive research on epidemiology and measures for control of LF in the past e.g. [24-30]. Prior to start-up of the NLFEP-activities in Tanga Region in 2004, no control had taken place in any of the sites used in the present study. In consistency with this, it was noted that pre-MDA indices of LF infection and transmission were very high and resembled those reported during earlier studies in nearby areas. High levels of clinical manifestations were also recorded in Kirare study community, and were moreover strikingly visible when moving around in the area.

The study design and methodology and the effects of MDAs in the early study period was reported previously for Kirare [6] and the 10 schools [7]. Some changes in study design and methodology in the community study were necessitated in later study period. First, increasing study fatigue among inhabitants of Kirare resulted in decreasing survey coverage from one MDA to the next. This was not only due to the yearly blood sampling, but also to some political rivalry among groups of villagers. As a consequence, it was decided to leave out two of the village hamlets and instead focus more attention on the remaining two hamlets where most cooperation was met. To compensate for the smaller survey population in Kirare, two other communities were included, whereby also a larger geographical area was covered. Second, due to the reduced human infection burden after the first MDAs there was a need to adopt a new and more practical diagnostic approach. The primary community screening tool was therefore changed from mf-testing to CFA-testing by ICT cards [31], followed by examination of only CFA positive individuals for $\mathrm{mf}$. As it was still essential to have an idea about the mf prevalence and intensity in the community (as indicators of availability of infection to the vectors), methods for calculating these indices based on the new screening procedure were developed. Third, the availability of a new commercial kit for examination of dried finger prick blood spots on filter paper eliminated the need for venous blood sampling in the later part of the study and made it practically feasible to examine larger populations for antibodies to Bm14. The changes in methods for measuring both CFA and antibodies to Bm14 are not likely to have had a major impact on the obtained results, but should still be kept in mind when analysing and interpreting the findings. In contrast to the opposition sometimes experienced from villagers during the human surveys, the trapping of mosquitoes in the 50 houses of Kirare generally proceeded smoothly throughout the study period.

In Kirare, the $\mathrm{mf}$ prevalence and community $\mathrm{mf}$ GMI generally decreased progressively with increasing number of MDAs. An exception to this was survey 5, where slight but statistically insignificant increases in these indices were seen, most likely due to the long interval between MDA 3 and 4 (21 months). An increase in mf and CFA was reported from Haiti after a single MDA with DEC/ albendazole had been missed [32], and both of these observations therefore seem to emphasize the importance of keeping a relatively short spacing between the MDAs. Decreases in $\mathrm{mf}$ prevalence and community $\mathrm{mf}$ GMIs were also obvious between survey 7 and 8 in the two new 
communities. Mf GMIs calculated on the basis of mf positive individuals generally remained high throughout the study, suggesting that some $\mathrm{mf}$ positive individuals regularly either avoided or were left out from treatment during the MDAs (systematic non-compliance). These individuals comprise an important source of $\mathrm{mf}$ for the continued transmission of LF.

CFAs are primarily released by adult $W$. bancrofti, and their presence is a sensitive and specific indirect measure of adult worm infection [16]. In the early study period, when CFAs were measured by ELISA, the decrease in CFA prevalence in Kirare was small. A more substantial decrease was seen in the GMIs, most likely because intensities were extremely high in the early period of the study. Thus, although intensities decreased they only reached the cut-off level for positivity in a few individuals [33]. In the late study period, when CFAs were measured with ICT cards, prevalences were substantially lower, and a continuing and statistically significant decrease was seen between survey 7 and 8 in all three communities. The two tests for CFA detection (ELISA and ICT cards) have been shown to be well in agreement when measuring CFA status [34]. Although the community CFA prevalence decreased considerably from the pre-MDA survey to survey 8 , it was still quite high after 6 MDAs.

The specific antibody response to the filarial antigen Bm14 is used as an indirect marker of exposure to $W$. bancrofti transmission $[21,35]$. In the early part of the study the Bm14 antibodies were measured with ELISA (by using antigen donated by Prof. G. Weil through the NIH/NIAID Filariasis Research Repository Centre, Smith College, USA) and all age-groups were examined, whereas in the later part of the study tests were performed with a commercially available test-kit (with antigen from the same source) and only included children aged 5-14 years. Although the different techniques used and age groups examined prevent exact comparisons, the very pronounced decrease in both prevalence and OD-value GMI between the pre-MDA survey and survey 8 in Kirare indicated that a major decrease in exposure to transmission had taken place in the human population, which is also in alignment with the findings from the entomological surveillance.

The vector species composition changed considerably during the study period from predominantly anopheline during the pre-MDA period, to almost exclusively culicine in the late study period. This remarkable shift has been documented and analysed in more detail elsewhere $[36,37]$. With respect to the role of the MDAs, there is documented evidence that anopheles mosquitoes taking a blood meal on ivermectin treated individuals show increased mortality [38], and that MDAs for LF in this way may affect transmission of malaria [39]. It is, however, difficult immediately to accept that the MDAs should be a primary cause for the shift, and a multitude of factors, including those related to environmental and climate change may be involved. Whatever the reason, there can be no doubt that the shift has important consequences for the epidemiology and control of LF, as the anopheline and culicine vector species differ in biology, biting habits and vectorial capacity. In addition to the shift in species composition there were marked seasonal fluctuations in vector abundance, with most vectors being present during and shortly after the two annual rainy seasons. Transmission was also most intense, and during the late period of the study only observed, in these seasons.

Transmission, assessed by dissection of vectors and recovery of L3s, decreased after each MDA, from high levels in the pre-MDA period to very low levels in the post MDA 6 period. It is likely that most of the decrease in transmission was due to the MDAs, which reduced the availability of microfilariae in the human population to the vectors. However, part of the decrease may also be due to the shift in vector species composition, whereby long-lived strongly anthropophilic anophelines (and thereby highly efficient vectors) were replaced by shorter lived and less strongly anthropophilic culicines (and thereby less efficient vectors) [12]. In the later period of the study, only very few infective mosquitoes were identified despite large numbers of vectors being dissected. Collection and dissection of vectors is a time-consuming and expensive task, but it provides the most exact information about vector dynamics and transmission of LF and as such is an important research tool for detailed investigation of transmission [40]. Newly developed PCR techniques may replace the laborious dissection activity in future assessments. However, the number of mosquitoes to be collected, and the efforts to be invested in collecting them, in order to get statistical reliable information about change in transmission intensity in the late period of control programmes may be enormous. In the present study, where mosquitoes were collected one night each week from 50 houses by use of light traps, too few were obtained to demonstrate a statistical change in transmission after post MDA 3 (although a decreasing trend was seen). Under these conditions, either much more effective mosquito collection methods are needed or indirect assessment methods such as measurement of CFA or antibodies to Bm14 in the human population (especially children) have to be employed.

The school based study was used as an alternative approach to assess the effect of MDAs on transmission in the area. The idea being that a reduced transmission will lead to reduced acquisition of infection in young children, and thereby a reduction in prevalence of CFA when examining children of the same age from year to year after start of MDA [7]. Indeed, after the first three MDAs the CFA prevalence in the new intake of Standard 1 pupils decreased rapidly, and thus provided a strong 
indirect indication that children were less and less exposed to infection from year to year after start of MDA. Further decrease in CFA prevalence was noted in the last two surveys, but the effect levelled off and the prevalence was still $5.6 \%$ in survey 8 . The majority of children examined during the last two surveys were aged one year or less when the first MDA was administered in 2004 (67.7\% in survey 7 and $90.7 \%$ in survey 8 ) and among these the CFA prevalence (5.9\% in survey 7 and $5.1 \%$ in survey 8) was comparable to the overall CFA prevalence for these surveys. Examination of the Standard 1 pupils from four of the schools for Bm14 antibody in survey 7 and 8 showed relatively high rates of positivity. However, the significant reduction in both $\mathrm{Bm} 14$ prevalence and OD-value GMI between these two surveys suggests that transmission was on the decrease.

Sustained high drug-intake coverage during MDAs for LF control is critical in order to reach the programme target within a reasonable time-frame, in particular in areas like the present with very high pre-MDA levels of infection [41,42]. Treatment coverage and compliance are therefore important factors to consider when monitoring and assessing the impact of MDAs, but reliable information is difficult to get. In the present study we used three different approaches to assess treatment coverage, namely the official "reported coverage" from NLFEP for Tanga District and two "surveyed coverages" obtained from interviews carried out shortly after each MDA in the study communities (individuals aged 5 years and above) and the study schools (Standard 1 pupils), respectively. Apart from MDA 1, where all three approaches indicated about $80 \%$, the surveyed coverages were considerably lower than the reported coverage, in particular for the Standard 1 pupils. The discrepancy in treatment coverage obtained by different approaches in this area, and the possible courses, was recently addressed in detail in a social science study [43], and only few comments related specifically to observations at the present study sites will be added. Firstly, there were frequent complaints from inhabitants in the study communities that they were not well informed by the programme about the drug distributions beforehand, neither regarding timing or purpose. Second, it was noted by the research team that the method for drug distribution varied between different MDAs and different sites, and obviously house-to-house distribution was more effective than distribution from a central village point. The very low coverages among the Standard 1 children, especially during the last three MDAs were noted to be related to: drug distribution during school holidays, some schools had no distribution point nearby, and parents refusing treatment of their children due to rumours of side effects. Finally, the activities of the research project probably created extra awareness about LF and its control in the study communities, which may have resulted in higher treatment coverages during MDAs than in other communities in the area. These important issues should be addressed in subsequent treatment rounds, in order to ensure sufficient treatment coverage, and thereby effectiveness, of the MDAs.

\section{Conclusions}

The present study demonstrated that, when compared to the pre-MDA scenario, six MDAs resulted in considerable decrease in infection and transmission of LF in the study populations, whether these were communities or schools and whether measures were based on detection of $\mathrm{mf}$, CFA, antibodies to Bm14 or mosquito vector dissections. In spite of this, there is still some way to go before the recommended target cut-off level of 1\% CFA for interrupting transmission and stopping MDA [14] is reached, and it may take a long time unless extra efforts are made. These should particularly include strengthened information dissemination to - and engagement of - the target populations in control activities, to ensure higher treatment coverages. The drawbacks that may be caused by much delayed MDAs should be avoided, and perhaps even more frequent treatments may be necessary in the last phase of the programme. Environmental management to limit breeding of the $C x$. quinquefasciatus vectors should also be encouraged. It is likely that the recent initiative to distribute insecticide impregnated bed nets to every household in the area will contribute substantially to further transmission reduction $[41,42]$, but also for this measure to show its full potential the importance of thoroughly informing and engaging the target communities should not be underestimated. Monitoring and evaluation will continue to play an important role to guide the programme and to ensure that the current major achievements will ultimately lead towards the goal of successful LF elimination.

\section{Competing interests}

The authors declare that they have no competing interests.

\section{Authors' contributions}

PES, YAD, WK, SMM, MNM and EMP conceived and designed the experiments. PES, YAD, SMM and EMP performed the experiments. PES, YAD and EMP analysed the data. PES, YAD and EMP wrote the paper. All authors read and approved the final manuscript.

\section{Acknowledgements}

The authors are grateful to the villagers and village helpers in Kirare, Kiomoni and Kisimatui and to the children and their teachers in the study schools for their dedicated cooperation, to the technical staff from Amani Medical Research Centre Filariasis Laboratory in Tanga (Kassembe Mdira, Charles Mbezi, Maembe Mzee, Justin Mkeni, Demitrius Max, John Samwel) for their skilled assistance in the field and the laboratory, to the NLFEP officer for Tanga Region (Rehema Maggid) for providing data on the district treatment coverages, and to the technician from DBL in Denmark (Jakob Felsager) for meticulously performing the Bm14 CELISAs. The study received financial support from Danida Development Research Council (grant no. 09-096LIFE) and DBL-Centre for Health Research and Development, University of Copenhagen. 


\section{Author details}

${ }^{1} \mathrm{DBL}$ - Centre for Health Research and Development, Faculty of Health and Medical Sciences, University of Copenhagen, Thorvaldsensvej 57, 1871 Frederiksberg C, Denmark. ${ }^{2}$ Amani Medical Research Centre, National Institute for Medical Research, P.O. Box 81, Muheza, Tanzania. ${ }^{3}$ RTI International, International Development Group, Nairobi, Kenya. ${ }^{4}$ National Institute for Medical Research, P.O. Box 9653, Dar es Salaam, Tanzania.

Received: 10 November 2012 Accepted: 17 July 2013

Published: 21 July 2013

\section{References}

1. Hotez PJ, Kamath A: Neglected tropical diseases in Subsaharan Africa: Review of their prevalence, distribution, and disease burden. PLoS Negl Trop Dis 2009, 3(8):e412.

2. Simonsen PE: Filariases. In Manson's Tropical Diseases. 22nd edition. Edited by Cook GC, Zumla Al. London, UK: Saunders Elsevier; 2009:1477-1513.

3. Zeldenryk LM, Gray M, Speare R, Gordon S, Melrose W: The emerging story of disability associated with lymphatic filariasis: A critical review. PLoS Negl Trop Dis 2011, 5(12):e1366.

4. WHO: Lymphatic filariasis. Progress report 2000-2009 and strategic plan 2010-2020. Geneva, Switzerland: World Health Organization; 2010.

5. Malecela MN, Lazarus W, Mwingira U, Mwakitalu E, Makene C, Kabali C, Mackenzie C: Eliminating LF: A progress report from Tanzania. J Lymphoedema 2009, 4:10-12.

6. Simonsen PE, Pedersen EM, Rwegoshora RT, Malecela MN, Derua YA Magesa SM: Lymphatic filariasis control in Tanzania: Effect of repeated mass drug administration with ivermectin and albendazole on infection and transmission. PLoS Negl Trop Dis 2010, 4(6):e696.

7. Simonsen PE, Magesa SM, Derua YA, Rwegoshora RT, Malecela MN, Pedersen EM: Monitoring lymphatic filariasis control in Tanzania: effect of repeated mass drug administration on circulating filarial antigen prevalence in young schoolchildren. Int Health 2011, 3:182-187.

8. McMahon JE, Marshall TF d C, Vaughan JP, Abaru DE: Bancroftian filariasis: a comparison of microfilariae counting techniques using counting chamber, standard slide and membrane (nuclepore) filtration. Ann Trop Med Parasitol 1979, 73:457-464

9. Joseph HM, Melrose W: Applicability of the filter paper technique for detection of antifilarial lgG4 antibodies using the $\mathrm{Bm} 14$ filariasis CELISA J Parasitol Res 2010, 594687. doi:10.1155/2010/594687.

10. Weil GJ, Curtis KC, Fischer PU, Won KY, Lammie PJ, Joseph H, Melrose WD, Brattig NW: A multicenter evaluation of a new antibody test kit for lymphatic filariasis employing recombinant Brugia malayi antigen Bm-14. Acta Trop 2011, 120S:S10-S22.

11. Simonsen PE, Niemann L, Meyrowitsch DW: Wuchereria bancrofti in Tanzania: microfilarial periodicity and effect of blood sampling time on microfilarial intensities. Trop Med Int Health 1997, 2:153-158.

12. Rwegoshora RT, Pedersen EM, Mukoko DA, Meyrowitsch DW, Masese N, Malecela-Lazaro MN, Ouma JH, Michael E, Simonsen PE: Bancroftian filariasis: patterns of vector abundance and transmission in two East African communities with different levels of endemicity. Ann Trop Med Parasitol 2005, 99:253-265.

13. Michael E, Malecela-Lazaro MN, Maegga BTA, Fischer P, Kazura JW: Mathematical models and lymphatic filariasis control: monitoring and evaluating interventions. Trends Parasitol 2006, 22:529-535.

14. WHO: Monitoring and epidemiological assessment of mass drug administration in the global programme to eliminate lymphatic filariasis: A manual for national elimination programmes. Geneva, Switzerland: World Health Organization; 2011.

15. Ramzy RMR, El Setouhy M, Helmy H, Ahmed ES, Elaziz KMA, Farid HA, Shannon WD, Weil GJ: Effect of yearly mass drug administration with diethylcarbamazine and albendazole on bancroftian filariasis in Egypt: A comprehensive assessment. Lancet 2006, 367:992-999.

16. Weil GJ, Kastens W, Susapu M, Laney SJ, Williams SA, King CL, Kazura JW, Bockarie MJ: The impact of repeated rounds of mass drug administration with diethylcarbamazine plus albendazole on bancroftian filariasis in Papua New Guinea. PLoS Negl Trop Dis 2008, 2(12):e344.

17. Mitja O, Paru R, Hays R, Griffin L, Laban N, Samson M, Bassat Q: The impact of a filariasis control program on Lihir Island, Papua New Guinea. PLoS Negl Trop Dis 2011, 5(8):e1286.

18. Liang JL, King JD, Ichimori K, Handzel T, Pa'au M, Lammie PJ: Impact of five annual rounds of mass drug administration with diethylcarbamazine and albendazole on Wuchereria bancrofti infection in American Samoa. Am J Trop Med Hyg 2008, 78:924-928.

19. Mlandonicky JM, King JD, Liang JL, Chambers E, Pa'au M, Schmaedick MA, Burkot TR, Bradley M, Lammie PJ: Assessing transmission of lymphatic filariasis using parasitologic, serologic, and entomologic tools after mass drug administration in American Samoa. Am J Trop Med Hyg 2009, 80:769-773.

20. Ramaiah KD, Vanamail P, Yuvaraj J, Das PK: Effect of annual mass administration of diethylbarbamazine and albendazole on bancroftian filariasis in five villages in south India. Trans R Soc Trop Med Hyg 2011, 105:431-437.

21. Joseph H, Maiava F, Naseri T, Silva U, Lammie P, Melrose W: Epidemiological assessment of continuing transmission of lymphatic filariasis in Samoa. Ann Trop Med Parasitol 2011, 105:567-578,

22. Richards FO, Eigege A, Miri ES, Kal A, Umaru J, Pam D, Rakers LJ, Sambo Y, Danboyi J, Ibrahim B, Adelamo SE, Ogah G, Goshit D, Oyenekan OK, Mathieu E, Withers PC, Saka YA, Jiya J, Hopkins DR: Epidemiological and entomological evaluations after six years or more of mass drug administration for lymphatic filariasis elimination in Nigeria. PLoS Neg Trop Dis 2011, 5(10):e1346.

23. King JD, Eigege A, Umaru J, Jip N, Miri E, Jiya J, Alphonsus KM, Sambo Y, Graves P, Richards F: Evidence for stopping mass drug administration for lymphatic filariasis in some, but not all local government areas of Plateau and Nasarawa States, Nigeria. Am J Trop Med Hyg 2012, 87:272-280

24. McMahon JE, Magayuka SA, Kolstrup N, Mosha FW, Bushrod FM, Abaru DE: Studies on the transmission and prevalence of bancroftian filariasis in four coastal villages of Tanzania. Ann Trop Med Parasitol 1981, 75:415-431.

25. Kolstrup N, McMahon JE, Magayuka SA, Mosha FW, Bushrod FM: Control measures against bancroftian filariasis in coastal villages in Tanzania. Ann Trop Med Parasitol 1981, 75:433-451.

26. Meyrowitsch DW, Simonsen PE, Makunde WH: Bancroftian filariasis: analysis of infection and disease in five endemic communities of north-eastern Tanzania. Ann Trop Med Parasitol 1995, 89:653-663.

27. Meyrowitsch DW, Simonsen PE, Magesa SM: Long-term effect of three different strategies for mass diethylcarbamazine administration in bancroftian filariasis: follow-up at 10 years after treatment. Trans $R$ Soc Trop Med Hyg 2004, 98:627-634.

28. Simonsen PE, Meyrowitsch DW, Makunde WH, Magnussen P: Bancroftian filariasis: the pattern of microfilaraemia and clinical manifestations in three endemic communities of northeastern Tanzania. Acta Trop 1995, 60:179-187.

29. Simonsen $P E$, Meyrowitsch DW, Jaoko WG, Malecela MN, Mukoko D, Pedersen EM, Ouma JH, Rwegoshora RT, Masese N, Magnussen P, Estambale BBA, Michael E: Bancroftian filariasis infection, disease, and specific antibody response patterns in a high and a low endemicity community in East Africa. Am J Trop Med Hyg 2002, 66:550-559.

30. Simonsen PE, Magesa SM, Dunyo SK, Malecela-Lazaro MN, Michael E: The effect of single dose ivermectin alone or in combination with albendazole on Wuchereria bancrofti infection in primary school children in Tanzania. Trans R Soc Trop Med Hyg 2004, 98:462-472.

31. Weil GJ, Ramzy RMR: Diagnostic tools for filariasis elimination programs. Trends Parasitol 2006, 23:78-82.

32. Won KY, de Rochars MB, Kyelem D, Streit TG, Lammie PJ: Assessing the impact of a missed mass drug administration in Haiti. PLoS Neg/ Trop Dis 2009, 3(8):e443.

33. Simonsen PE, Magesa SM, Meyrowitsch DW, Malecela-Lazaro MN, Rwegoshora RT, Jaoko WG, Michael E: The effect of eight half-yearly single-dose treatments with DEC on Wuchereria bancrofti circulating antigenaemia. Trans R Soc Trop Med Hyg 2005, 99:541-547.

34. Simonsen PE, Dunyo SK: Comparative evaluation of three new tools for diagnosis of bancroftian filariasis based on detection of specific circulating antigens. Trans R Soc Trop Med Hyg 1999, 93:278-282.

35. Tisch DJ, Bockarie MJ, Dimber Z, Kiniboro B, Tarongka N, Hazlett FE, Kastens W, Alpers MP, Kazura JW: Mass drug administration trial to eliminate lymphatic filariasis in Papua New Guinea: change in microfilaraemia, filarial antigen, and Bm14 antibody after cessation. Am J Trop Med Hyg 2008, 78:289-293.

36. Meyrowitsch DW, Pedersen EM, Alifrangis M, Scheike TH, Malecela MN, Magesa SM, Derua YA, Rwegoshora RT, Michael E, Simonsen PE: Is the current decline in malaria burden in sub-Saharan Africa due to a decrease in vector population? Malaria J 2011, 10:188. 
37. Derua YA, Alifrangis M, Hosea KM, Meyrowitsch DW, Magesa SM, Pedersen EM, Simonsen PE: Change in composition of the Anopheles gambiae complex and its possible implications for the transmission of malaria and lymphatic filariasis in north-eastern Tanzania. Malaria J 2012, 11:118.

38. Chaccour C, Lines J, Whitty CJM: Effect of ivermectin on Anopheles gambiae mosquitoes fed on humans: the potential of oral insecticides in malaria control. J Infect Dis 2010, 202:113-116.

39. Kobylinski KC, Sylla M, Chapman PL, Sarr MD, Foy BD: Short report: Ivermectin mass drug administration to humans disrupts malaria parasite transmission in Senegalese villages. Am J Trop Med Hyg 2011, 85:3-5.

40. Pedersen EM, Stolk WA, Laney SJ, Michael E: The role of monitoring mosquito infection in the Global Programme to Eliminate Lymphatic Filariasis. Trends Parasitol 2009, 25:319-327.

41. Michael E, Malecela-Lazaro MN, Simonsen PE, Pedersen EM, Barker G Kumar A, Kazura JW: Mathematical modelling and the control of lymphatic filariasis. Lancet Infect Dis 2004, 4:223-234.

42. Michael E, Malecela-Lazaro MN, Kabali C, Snow LC, Kazura JW: Mathematical models and lymphatic filariasis control: endpoints and optimal interventions. Trends Parasitol 2006, 22:226-233.

43. Parker $M$, Allen $\mathrm{T}$ : Will mass drug administration eliminate lymphatic filariasis? Evidence from northern coastal Tanzania. J Biosoc Sci 2013, 45:517-543. 10.1017/\$0021932012000466.

doi:10.1186/1471-2334-13-335

Cite this article as: Simonsen et al:: Lymphatic filariasis control in Tanzania: effect of six rounds of mass drug administration with ivermectin and albendazole on infection and transmission. $B M C$ Infectious Diseases 2013 13:335.

\section{Submit your next manuscript to BioMed Central and take full advantage of:}

- Convenient online submission

- Thorough peer review

- No space constraints or color figure charges

- Immediate publication on acceptance

- Inclusion in PubMed, CAS, Scopus and Google Scholar

- Research which is freely available for redistribution 